\title{
Effect of Diesel Oil , Sodium Oleate and Hydroxyethylcellulose (HEC) as Retarders on Hydration of Lime
}

\author{
Sury Narayan Yadav,", Ram Nath Singh \\ Post Graduate Centre Of Chemistry, College of Commerce Patna(M.U.), India
}

Copyright (C) 2015 Horizon Research Publishing All rights reserved.

\begin{abstract}
Effect of various additives on hydration of lime has been carried out. Lime which is formed by the calcining of lime stone $\left(\mathrm{CaCO}_{3}\right)$ at $1000^{\circ} \mathrm{C}$ is of great importance. As, it is used in laboratory as reagent, in the manufacture of bleaching powder, glass \& steel making, in agriculture as source of calcium and in water treatment, neutralization of soil acidity etc. More than $72 \%$ of lime stone is used in the manufacture of cement. Though free lime does not found in properly made Portland cement (generally found in its hydrated form) but it plays an important role in the setting of cement. Sometimes fast reactivity of lime decreases the strength of set cement due to false setting. By adding certain chemicals (retarders), the hydration of lime can be slowed down and it may help in overall increase in setting time as well as strength of set cement. Various additives -called retarders - are added to inhibit the setting of cement such as gypsum, sucrose etc.
\end{abstract}

Keywords Diesel Oil, Sodium Oleate, Hydroxyethylcellulose (HEC), Retarders, Hydration of Lime

\section{Introduction}

The retarders are of great importance, as it is used in various fields such as in cement industries, corrosion retardation, fire retardation, pollution retardation, soil erosion retardation, acidity of soil retardation, in human health as bacteria retardation etc. This study includes the determination of available lime and the slaking rate of lime in presence of other chemicals. Though this study may not have direct application in cement industries but it may serve a guide for similar reactions where reactivity of lime with water is applied for specific use. This work is aimed to find out a suitable chemicals or additives which can delay the reactivity of lime with water.

\section{General properties of Chemicals used for study:}

\section{(i) Diesel oil :}

It is a hydrocarbon having carbon atom $\mathrm{C}_{16}-\mathrm{C}_{20}$ and is obtained from an intermediate weigh petroleum components having boiling points between kerosene and lubricating oils (i.e. 419-487, Welker 1985). Actually, diesel oil form an emulsion in distinct layer with water. It has ability to suspend the solid particles. It is brown coloured liquid having some smell.

(ii) Sodium Oleate : It is made from oleic acid having molecular formula $\mathrm{C}_{18} \mathrm{H}_{33} \mathrm{O}_{2} \mathrm{Na}$. Its structural formula is as, (Finar 1973 and Howley 1950) :

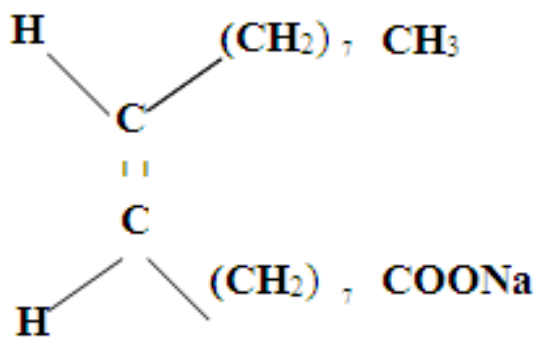

\section{Cis Form}

(iii) Hydroxyethylcellulose (HEC) :

It is Cellulose ether, formed by the reaction between ethylene oxide and cellulose. Two types of derivatives have been obtained, one is water soluble and other is alkali soluble. The main uses of water soluble derivatives are based on non-ionic character, resistance to heat getting. Application includes pigment carrier in printing pastes, protective colloids in electroplating and binder in ceramic (Snell et al, 1977).

While alkali soluble type of HEC is used for making extruded film which has exceptional dimensional stability, sparkle and clarity. It is used in certain textile sieving and finishing treatments. 


\section{Experimental}

a) Determination of Slaking Rate:

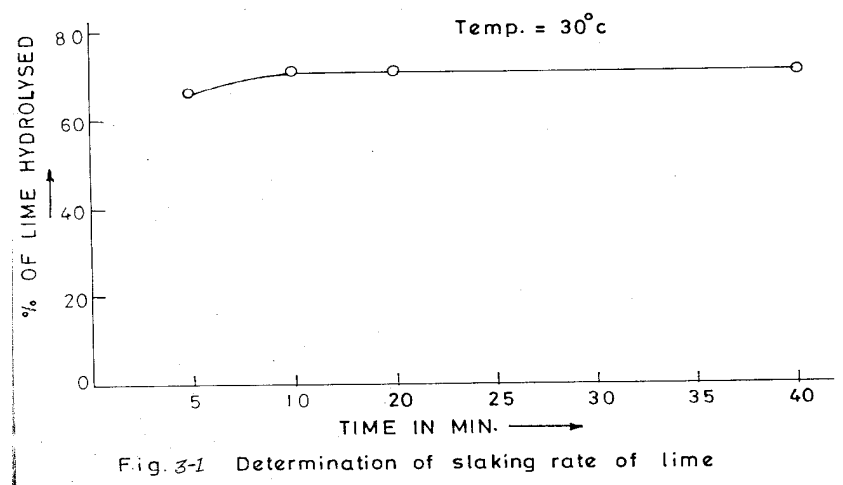

Slaking rate determines the reactivity of lime. Lime which is completely hydrolysed within 5 - 10 minutes is called highly reactive and hydrolysed between $10-20$ minutes is medium range reactive while hydrolysed after 20 minutes is low reactive.

For determining the slaking rate ,50 $\mathrm{mg}$ of lime was added to $50 \mathrm{ml}$ of distilled water taken in a beaker, left it for 5 minutes and then kept in ice to freeze the further reaction. A drop of PR indicator was added to the solution and titrated against EDTA solution maintaining the $\mathrm{pH}$ value 10 , by adding $1 \mathrm{M} \mathrm{NaOH}$. The whole solution was stirred on magnetic stirrer. At the end point colour of the solution changed from pink to clear blue.

Similar experiments were performed at the interval of 10 minutes, 20 minutes, 40 minutes and 1 hour respectively and data were recorded.

After calculation and plotting the graph, it was concluded that most of the $71 \%$ available lime (i.e. $68.2 \%$ ) hydrolysed within 5 minutes and rest $(2.7 \%)$ completely hydrolysed within 10 minutes shown in fig.3-1.

\section{b) Reaction of Lime in Diesel Oil:}

\section{Procedure :}

$40 \mathrm{mg}$ of lime was added to oil water mixture $(5 \mathrm{ml}$ oil $50 \mathrm{ml}$ water), $\mathrm{pH}$ of this solution was measured by $\mathrm{pH}$ paper because $\mathrm{pH}$ meter was not effective in oil medium and a drop of PR indicator was added to the solution and required volume of EDTA solution was added at a time. The whole solution in a beaker was stirred on a magnetic stirrer. At the end point, colour of the solution changed from pink to blue. $\mathrm{pH}$ of the solution at the end point and time required for complete neutralization were measured. Same experiments were done in different proportions or ratio of oil - water mixture. The same observations were made in diesel oil water $(5: 50)$ at different temperatures i.e. $40^{\circ} \mathrm{C}$ and $20^{\circ} \mathrm{C}$ respectively and the data observed are shown in Table -1
\& fig. 3.5 .

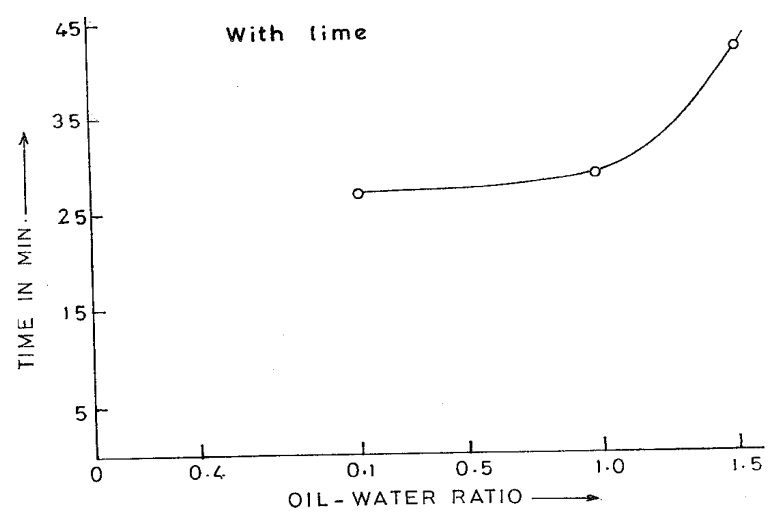

Fig. 3.5. Effect of diesel oil on the hydration of time

\section{Result and Discussion}

It was found that with increasing the proportion of oil in oil-water mixture, time required for complete neutralization of reaction increases. It indicates that diesel oil delayed the hydration of lime. Thus diesel oil acts as a retarder. But at higher temperature (i.e. $40^{\circ} \mathrm{C}$ ) the reaction is completed within two minutes i.e. the reaction could not slowed down rather accelerated. At lower temperature i.e. at $20^{\circ} \mathrm{C}$ reaction freezes.

c) Reaction of lime in sodium oleate solution of different concentrations:

(i) Preparation of 5\% sodium oleate solution:

$5 \mathrm{~g}$ sodium oleate was dissolved in $100 \mathrm{ml}$ distilled water. The mixture formed some foams. From this solution $0.01 \%$, $0.1 \%, 0.5 \%$ and $1 \%$ solution were prepared by dilution. $\mathrm{pH}$ of the different solutions were measured and then used for experiments.

\section{Procedure}

$40 \mathrm{mg}$ of lime (particles size - less than $75 \mu \mathrm{m}$ ) was added in $25 \mathrm{ml}$ of sodium oleate solution $\& \mathrm{pH}$ of the solution was measured. A pinch of PR indicator was added to it. The colour of the solution becomes pink. A required volume of EDTA solution was added at a time. The whole solution in a beaker was stirred on a magnetic stirrer. At the end point colour of the solution turned pink to clear blue. $\mathrm{pH}$ of the solution at the end point and time required for complete neutralization were measured. Similar experiments were carried out at different concentrations of sodium oleate. Then $0.5 \%$ sodium oleate, diesel oil mixture $(1: 1)$ were used . Observations made are given in Table -2 and fig.3.2.

Table 1. Effect of Diesel Oil in the Hydration of Lime

\begin{tabular}{|c|c|c|c|c|c|c|}
\hline $\begin{array}{c}\text { Ratio of Diesel Oil : } \\
\text { Water in ml. }\end{array}$ & $\begin{array}{c}\mathrm{pH} \text { of Diesel } \\
\text { oil }\end{array}$ & $\begin{array}{c}\mathrm{pH} \text { of } \\
\text { solution }\end{array}$ & $\begin{array}{c}\mathrm{pH} \text { at end } \\
\text { point }\end{array}$ & \% of Lime & $\begin{array}{c}\text { Time required for } \\
\text { end point }\end{array}$ & \begin{tabular}{c} 
Indi-cator \\
\hline $5: 50$
\end{tabular} \\
\hline $10: 10$ & & 11.0 & 9.0 & 71 & $27 \mathrm{~min}$. \\
\hline $15: 10$ & 10.0 & 8.5 & & $29 \mathrm{~min}$. & PR \\
\hline
\end{tabular}


Table 2. Effect of Sodium Oleate on the Hydration of Lime

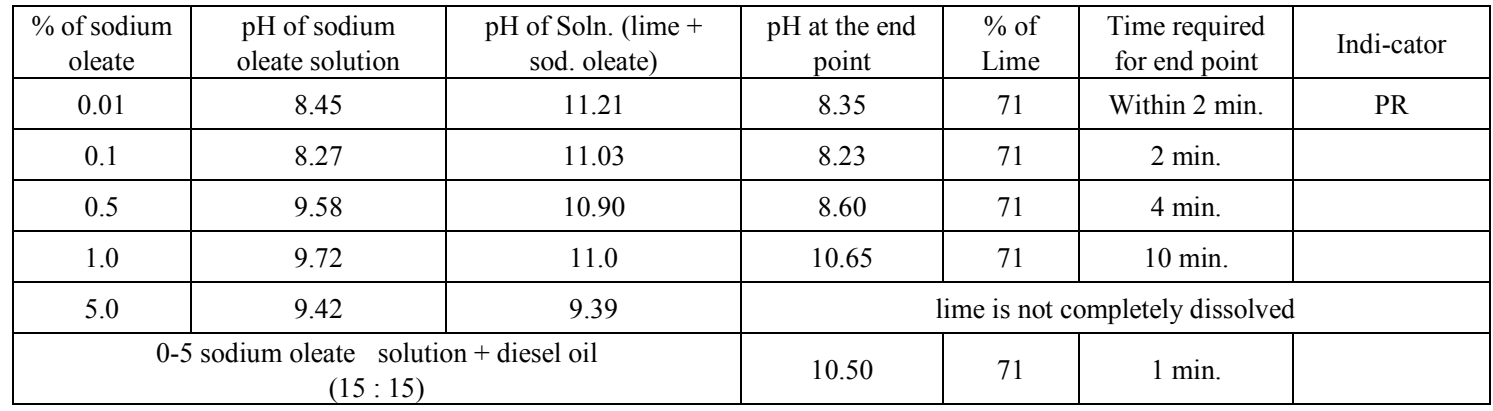

Table 3. Effect of HEC on Hydration of Lime

\begin{tabular}{|c|c|c|c|c|c|c|}
\hline \% of HEC solution & $\begin{array}{c}\mathrm{pH} \text { of the HEC } \\
\text { soln. }\end{array}$ & $\begin{array}{c}\mathrm{pH} \text { of the } \\
\text { soln. (lime }+ \\
\text { HEC) }\end{array}$ & $\begin{array}{c}\mathrm{pH} \text { at end } \\
\text { point }\end{array}$ & \% of lime & $\begin{array}{c}\text { Time required for } \\
\text { end point }\end{array}$ & $\begin{array}{c}\text { Indi-cator } \\
1 \mathrm{~min} .\end{array}$ \\
\hline 0.5 & 11.35 & 11.06 & 11.14 & 71 & $1 \mathrm{~min}$. \\
\hline 1.10 & 11.45 & 11.08 & 11.15 & 71 & $1 \mathrm{~min}$. \\
\hline
\end{tabular}

\section{Result and Discussion}

From Table 3 and Fig. 3 it is observed that with increasing concentrations of sodium oleate solution, time required for complete neutralization has increased. It indicated that hydration of lime can be delayed by increasing the concentration of sodium oleate solution. But after certain concentration lime was not hydrolysed. It indicates that sodium oleate acts as a reaction retarder. In diesel oil sodium oleate solution, it acts as reaction accelerator.

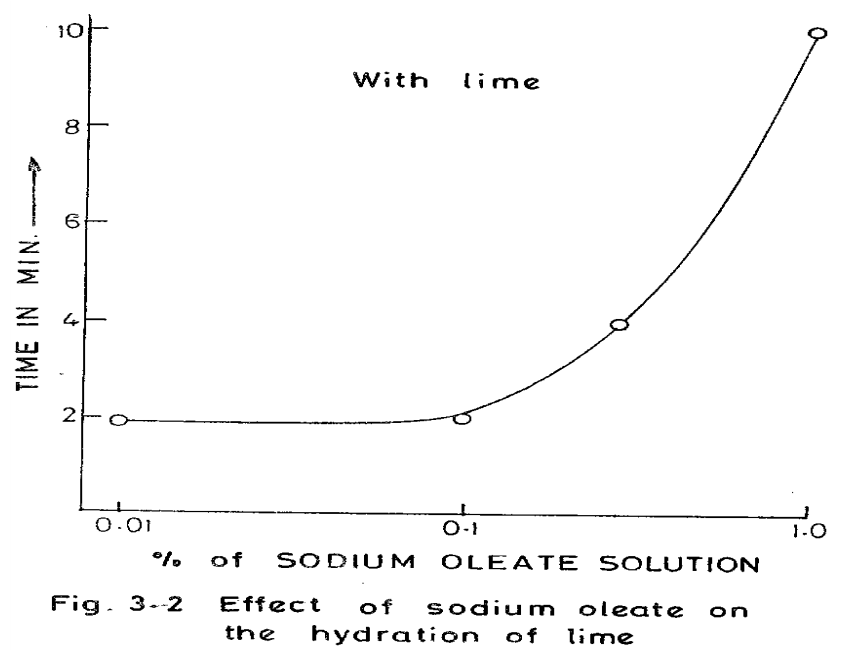

d) Reaction with Hydroxy Ethyl Cellulose( HEC)

$1 \mathrm{gm}$ of HEC was dissolved in $100 \mathrm{ml}$ distilled water. Since HEC did not dissolved easily in water therefore 1 or 2 drops of $\mathrm{NaOH}$ was added to it. The whole solution in a beaker was stirred on a magnetic stirrer. From this $1 \%$ solution, $0.5 \%$ solution made by dilution. The $\mathrm{pH}$ of solution was measured and then used for the experiment.

Procedure:

$40 \mathrm{mg}$ of lime was added to $25 \mathrm{ml}$ of HEC solution. The
$\mathrm{pH}$ of this solution was measured. A pinch of PR indicator was added to it. A required amount of EDTA solution was added at a time. The whole solution in a beaker was stirred on a magnetic stirrer. At the end point the colour of the solution turned pink to clear blue. The $\mathrm{pH}$ of the neutral solution and the time required for complete neutralization were measured. Similar experiments were done in $1 \% \mathrm{HEC}-$ diesel oil mixture $(1: 1)$ and same with $1 \%$ HEC solution at $40^{\circ} \mathrm{C}$ and $20^{\circ} \mathrm{C}$. The observed data are shown in Table 3.

\section{Result and Discussion}

From Table 3 it is clear that HEC in fact has accelerated the reaction even in diesel oil.

\section{Conclusions}

In present investigation, effects of different chemicals or additives (retarders) on the reactivity of lime with water were studied. Time required to attain the equilibrium for the reaction between lime and water under various conditions were measured. This was estimated by complex metric titration.

In each case $40 \mathrm{mg}$ of sample was added to $25 \mathrm{ml}$ of solution of desired chemicals. To ignore the effect of low diffusion rate on the reactivity of lime under static condition, the mixture was stirred on a magnetic stirrer constantly. This eliminated the possibility of high concentration of $\mathrm{Ca}(\mathrm{OH})_{2}$ in the vicinity of solid surface and thereby inhibiting the reaction. Different concentrations of sodium oleate, diesel oil and HEC were taken. The effects of these chemicals (sodium oleate and HEC) were also seen in diesel oil mixture.

It was seen that with $1 \%$ sodium oleate solution the reaction between lime and water can be delayed by 10 minutes - 12 minutes. In presence of diesel oil (3:2 ratio of oil-water) reaction was delayed by $40-42$ minutes. It was expected that these chemicals form a mechanical barrier 
around the solid particles and it can be dispersed. High molecular weight compound might had formed a viscous and strong three dimensional structure in the surface layer that retarded the reaction.

Retardation due to diesel oil might be due to adsorption of diesel oil on the calcium oxide surface. After addition of water, oil layer lead to depletion. It appeared that the reaction can be delayed further by controlling the depletion of oily layer.

After maintaining the temperature of the reaction mixture in one case at $40^{\circ} \mathrm{C}$ and in another at $20^{\circ} \mathrm{C}$, it was observed that at elevated temperature the reaction could not be slowed down. At $20^{\circ} \mathrm{C}$, reaction rate was found to have reduced appreciably.

\section{Acknowledgements}

The author (S.N. Yadav) thanks to I.S.M., Dhanbad for providing Research Fellowship and to Dr. D. Guha, Professor of Applied Chemistry, Indian School of Mines, Dhanbad, for his valuable suggestions and co-operation.

\section{REFERENCES}

[1] Hawley, G.G. [1950]. The Condensed Chemical Distionary. Van Nostrand Rainhold Company, New York; p. 803, 806.

[2] Finar, I.L. [1973]. Organic Chemistry, Vol. I; p.193

[3] Welker, A.J. [1985], The Oil and Gas Book.

[4] Snell, Foster Dec and Ettri, Leslie S. [1977] Encyclopedia of Industrial Chemical Analysis, Interscience Publisher, New York; Vol. 15; p., 9, 82.

[5] Ibid, vol. 15; p. 229-31.

[6] Vogel, A.I. [1978]. A Text Book of Quantitative Inorganic Analysis, Longman, Inc, New York; p. 321.

[7] Lee, F.M. [1970]. The Chemistry of Cement and Concrete, Edward Arnold Publishers Ltd., p. 29, 253-310.

[8] Flaschka, H.A. [1964]. EDTA Titration, Pergamon Press. 